\title{
WHY IRA AND KEOGH PLANS SHOULD AVOID GROWTH STOCKS
}

\author{
Uzi Yaari ${ }^{\star}$ and Frank J. Fabozzi $i^{\star *}$
}

\begin{abstract}
This paper explores the effect of taxing personal income from common stocks on the return of equity portfolios held by mutual funds under IRA or Keogh plans. The expected rate of return earned by a tax-sheltered fund on any given stock is inversely related to the stock's pershare growth rate. The explanation for this effect does not rely on the standard assumption that growth decreases the effective rate of taxation. Rather, this effect holds despite heavier taxation of growth stocks because of the incomplete manner in which the return is sheltered. The implication of this finding for the optimal portfolio selection policy of tax-sheltered equity funds is inconsistent with evidence showing that such funds tend to concentrate in growth stocks. A second issue examined is the use of IRA and Keogh plans as a temporary tax shelter. Under the present 10-percent penalty on premature distribution, the critical investment period may be as short as two to three years. This finding indicates the usefulness of these plans as a general investment tool.
\end{abstract}

\section{Introduction}

The dramatic rise in recent years in the dollar value of the common stock portfolio held by mutual funds under Individual Retirement Arrangements (IRA) or Keogh plans can be attributed to two developments. First, there has been an increase in the overall asset portfolio held by mutual funds. Between 1981 and 1984 the value of total assets held by mutual funds increased from 241.4 to 370.6 billion dollars. This included an increase from 37.9 to 78.0 billion dollars in assets held by funds concentrating in common stocks, reflecting in part an increase from 2.9 to 9.9 billion dollars in stock-invested IRA or Keogh funds (see Table 1). Second, changes in the tax law offer more liberal treatment to non-corporate retirement plans. The Employee Retirement Income Security Act of 1974 along with the Economic Recovery Tax Act of 1981 facilitate the establishment on a large scale of tax-exempt individual retirement plans, a significant portion of which went to mutual funds. This trend in government policy continues with the 1984 implementation of the Tax Equity and Fiscal Responsibility Act of 1982, which further relaxes limitations on such plans.

The IRA and Keogh plans have four essential features: (a) contributions into the plan are tax-exempt; (b) accumulation within the plan is tax-sheltered until distribution; (c) distributions are taxed as ordinary income or as capital gains, depending on the type of plan and the pace of distribution-but not on the historical division between dividends and capital gains in the accumulation of the fund; (d) distributions before the age of $591 / 2$ or beyond the age of $70^{1 / 2}$ are subject to an additional tax penalty. The third feature has a special policy implication for the sheltered fund. In an unsheltered mutual fund, the choice of stocks affects the return composition and the 
TABLE 1. IRA, Keogh, and Overall Funds Predominantly Invested in Common Stocks, Classified by Investment Objective.

(Year-End, Billions of Dollars)

\begin{tabular}{lccccc}
\hline & \multicolumn{2}{c}{ IRA and Keogh Portfolio } & & \multicolumn{2}{c}{ Overall Portfolio } \\
\cline { 2 - 3 } \cline { 5 - 6 } $\begin{array}{l}\text { Investment } \\
\text { Objective }\end{array}$ & 1981 & 1984 & & 1981 & 1984 \\
\hline Growth & $\$ 1.7$ & $\$ 4.3$ & & $\$ 15.2$ & $\$ 25.9$ \\
Growth-Income & 0.8 & 3.7 & & 18.2 & 32.7 \\
Income & 0.4 & 1.9 & & 4.5 & 19.4 \\
\hline Total & 2.9 & 9.9 & & 37.9 & 78.0 \\
\hline
\end{tabular}

Source: Mutual Fund Fact Book. (1982-1985) Washington, D.C.: Investment Company Institute.

effective tax rate paid by shareholders. This means that the optimal choice of stocks maximizing the post-tax return earned (at a given risk) by fund shareholders may not maximize the pre-tax return earned by the fund itself. In contrast, in a tax-sheltered fund the objective of maximizing the post-tax rate of return directly translates into a fund policy of maximizing the pre-tax rate of return. As an extension of this argument, if the stock market (including fund stocks) is dominated by taxpaying individuals of a given tax bracket, the selection of stocks by an unsheltered fund will have no effect on its post-tax return. Conversely, the selection of stocks will affect the post-tax return of a sheltered fund, where the shareholder tax rate is independent of the fund's composition of return. Other things being equal, the pre- and post-tax return of a sheltered fund would be increased by selecting stocks generating income which is subject to a heavier personal tax burden.

The current literature contains two conflicting theoretical views on the relationship between stock growth and tax burden. According to the traditional view, non-growth "income" stocks entail the heaviest tax burden because dividends are taxed at the full personal rate. This follows from the assumption that retention (growth) allows shareholders to substitute capital gains tax for dividend tax. Miller (1977) and Feldstein and Green (1983) are among many authors supporting this theoretical view, thereby implying that non-growth stocks are the best choice for tax-sheltered funds. Apparently reflecting this view, Donoghue recently recommended that "Money put aside for retirement in IRAs or Keoghs should be invested primarily to take advantage of the opportunity to tax-shelter dividends . . . and short-term capital gains" (1983, p. 164).

In a challenge to the traditional approach, Palmon and Yaari (1981) demonstrate that retention does not facilitate substitution between the two taxes, but adds the impact of capital gains tax in addition to the dividend tax. Their conclusion is that the personal tax burden increases with the stock's growth rate. 'Intuitive extension of this

\footnotetext{
'The available empirical evidence is ambiguous. For example, Black and Scholes (1974) and Miller and Scholes $(1978,1982)$ find no relationship between pre-tax dividend yields and stock returns; Long (1978) finds a negative relationship, inconsistent with the traditional claim and that of this paper; Litzenberger and Ramaswamy (1979) find a positive relationship, consistent with both claims. These studies test the validity of the CAPM as much as they test the hypothesis under consideration.
} 
conclusion would suggest that growth stocks are the best choice for tax-sheltered funds.

This paper extends the Palmon-Yaari analysis to the environment of tax-sheltered investment. The results are surprising on several levels. First, contrary to intuition, the return of the tax-sheltered fund is shown to maintain an inverse relationship to the growth rate of stocks held by the fund. This relationship holds not because of a lesser tax burden of growth stocks, but despite a heavier burden. Second, this result indicates that the traditional approach points in the right direction but for the wrong reason and to the wrong extent-resulting in a mis-specified rate of return that may lead fund management and fund shareholders to incorrect investment decisions. Third, the demonstrated inverse relationship between growth and return indicates that actual funds' behavior may be contrary to their shareholders' best interests. Table 1 shows that IRA and Keogh stock funds are predominantly invested in growth stocks, even more so than unsheltered stock funds where growth may have no adverse tax ramifications. During the three-year period 1982-1984, in 49 percent of the total stock portfolios held under these retirement plans, the main emphasis is on growth (i.e., capital gains). The combination of growth and income is emphasized in 36 percent of these portfolios, while only 15 percent are designed for income (i.e., dividends).

The remainder of this paper proceeds as follows. The traditional approach to the issue of growth and tax-sheltered return is examined in section II. A revised method for deriving the fund's return is presented in section III and is used to derive the personal return in section IV. The effect of growth on sheltered return is determined in section $\mathrm{V}$ and is contrasted with the traditional approach in section VI. The use of retirement funds for temporary tax-sheltering of investment is analyzed in section VII. A summary of the results appears in section VIII.

\section{Growth and Sheltered Return: The Traditional Approach}

According to the traditional view, the impact of personal taxation on income generated from common stocks is inversely related to their growth rate because retention replaces fully taxed dividends by capital gains that are both partially exempt from tax and subject to deferral. Consistently, a tax-sheltered fund invested in growth stocks instead of non-growth income stocks foregoes part of the advantage of the tax shelter. If all stocks held over a given time period are to yield the same risk-adjusted expected return after tax, growth stocks that avoid some of the tax should yield a lower sheltered return before tax.

To analyze this argument, consider a tax-sheltered investment in a single share of common stock. In the notations used below, $P_{0}$ and $P_{1}$ are the ex-dividend share prices at the beginning of the first and second years, respectively; $D$ is the dividend per share expected at the end of the first year; and $t_{d}$ and $t_{c}$, respectively, are the effective marginal tax rates on dividends and capital gains in the unsheltered market assumed to dominate the pricing of this stock. A one-year investment terminated by a sale of the share implies the post-tax rate of return,

$$
r=\frac{\left(P_{1}-P_{0}\right)\left(1-t_{c}\right)+D\left(1-t_{d l}\right)}{P_{0}}
$$


Under the traditional approach, a dollar of year-end earnings reinvested in the firm causes an expected increase of one dollar in the terminal price, $P_{1}$ (explicitly stated in Arditti et al., 1976, and Feldstein et al., 1979). On the basis of this assumption, the rate of return is written in terms of year-end earnings per share, $E$ (e.g., Bailey, 1969, Arditti et al., 1976, and Feldstein et al., 1979).

$$
r=\frac{E b\left(1-t_{c}\right)+E(1-b)\left(1-t_{d}\right)}{P_{0}}
$$

where $1-b$ is the payout ratio. Given the yield on incremental investments and their fraction financed internally, there is a direct relationship between the fraction of earnings retained, $b$, and the resulting share growth rate, $\left(P_{1}-P_{0}\right) / P_{0}$. Consistent with equation (2), the pre-tax rate of return earned by the sheltered fund on a share of stock held in its portfolio is written as

$$
r_{s}=\frac{E b+E(1-b)}{P_{0}}=\frac{E}{P_{0}}
$$

To determine the effect of retention and growth on $r_{s}$ in a market dominated by stockholders earning only $r$, the rate $r_{s}$ is substituted for $E / P_{0}$ in equation (2), which is then solved for $r_{s}$

$$
r_{s}=\frac{r}{b\left(1-t_{c}\right)+(1-b)\left(1-t_{d}\right)} .
$$

Under the assumption of $t_{d}>t_{c}$, the claimed negative effect of growth on the rate of return earned by the sheltered fund is confirmed by the sign of the partial derivative,

$$
\frac{\partial r_{s}}{\partial b}=\frac{-r\left(t_{d}-t_{c}\right)}{\left[b\left(1-t_{c}\right)+(1-b)\left(1-t_{d}\right)\right]^{2}}
$$

subject to the qualification that retention rather than growth is the true focus of this claim. ${ }^{2}$

\section{Analysis}

The sequence of arguments leading to the above conclusion of an inverse relationship between retention and sheltered return is fundamentally flawed. In particular,

\footnotetext{
2Palmon and Yaari (1983b) show that in the presence of personal taxes the ratio between the rates of retention and growth depends in a complex way on the rate of return of incremental investments, the fraction of these investments finance by equity, the fraction of equity financed internally, the discount rate, and the two tax rates.
} 
the substitution of the right-hand side of equation (2) for that of equation (1) is not legitimate since $E b \neq P_{1}-P_{0}$. The equality $E b=P_{1}-P_{0}$ assumed under the traditional approach implies that a dollar of undistributed corporate earnings, $E$, has a market value of a dollar; this condition cannot hold if future dividends are expected to be subject to the same personal tax ( $c f$. Palmon and Yaari, 1981). Retained funds avert current payment of dividend tax but the valuation of those funds does not escape the impact of the eventual payment of this tax. Consistently, the impact of capital gains tax should be calculated by applying this tax to the realized gain, $P_{1}-P_{0}$ (the price appreciation impounding the impact of the dividend tax), not to the funds retained, $E b$. The relationship stated in equation (5) flows directly from the erroneous substitution made in equation (2), and, therefore, cannot be valid.

\section{Sheltered Fund's Return: A Respecification}

This section is concerned with the derivation of a revised expression for $\boldsymbol{r}_{s}$ as a function of the underlying stock growth rate and other parameters. The inappropriate substitution made in equation (2) is avoided by developing an expression for $P_{0}\left(\right.$ and $\left.P_{1}\right)$ in a world of personal taxation, to be substituted in the following definition of the sheltered return,

$$
r_{s}=\frac{D+P_{1}-P_{0}}{P_{0}}
$$

To avoid ambiguity in tax consequences, the valuation formula developed below (following Yaari et al., 1980) assumes constancy of the stock's per-share growth rate, $g$, the associated retention rate, and the marginal effective tax rates and holding period dominating the market for that stock. Under the provisional assumption that the stock is traded annually, ex-dividend, ${ }^{3}$ the current share price will reflect the following perpetual cash flows,

$\begin{array}{cll}\text { End Year } & \text { Post-Tax Dividends } & \text { Capital Gains Tax } \\ 1 & D\left(1-t_{d}\right) & -P_{0} g t_{c} \\ 2 & D\left(1-t_{d}\right)(1+g) & -P_{0} g t_{c}(1+g) \\ \vdots & \vdots & \vdots \\ j & D\left(1-t_{d}\right)(1+g)^{i-1} & -P_{0} g t_{c}(1+g)^{j-1} \\ \vdots & \vdots & \vdots\end{array}$

${ }^{3}$ Trading at other points in the dividend cycle may impose a penalty on investors. The assumption of exdividend trading is not restrictive in view of the common practice of frequent distribution (see Palmon and Yaari. 1983a). 
Consistent with the use of a single marginal tax bracket and a single marginal holding period, these flows are discounted at a single risk-adjusted post-tax rate of return, $r$, assumed to dominate the market,

$$
P_{0}=\frac{D\left(1-t_{d}\right)}{r-g}-P_{0} t_{c} \frac{g}{r-g} \quad(r>g) .
$$

The price formula is obtained by solving the last equation for $P_{0},{ }^{4}$

$$
P_{0}=\frac{D\left(1-t_{d}\right)}{r-g\left(1-t_{c}\right)} \text {. }
$$

Contrary to the traditional approach, partial differentiation by the firm's retention ratio would show that the tax burden implied by this price increases rather than decreases with an increase in that ratio, regardless of the relationship between $t_{c}$ and $t_{d}$ (Palmon and Yaari, 1981).

Equation (8) can be expanded to allow for the effect of deferred trading on the impact of capital gains tax. To this end, the assumption of annual trading is relaxed to accommodate a marginal holding period of $i$ years $(1 \leq i \leq \infty)$ terminated by exdividend trading. Since this modification does not alter the impact of the dividend tax, it is introduced only to the second term of equation (7), by writing

$$
P_{0}=\frac{D\left(1-t_{d}\right)}{r-g}-P_{0} t_{s} \frac{(1+g)^{i}-1}{(1+r)^{i}-(1+g)^{i}}
$$

where $t_{s}$ is the statutory rate of capital gains tax or a lower effective tax rate excluding the consequences of deferral. The generalized price formula is

$$
P_{0}=\frac{D\left(1-t_{d}\right)}{r-g}\left[1+t_{s} \frac{(1+g)^{i}-1}{(1+r)^{i}-(1+g)^{i}}\right]^{-1} \text {. }
$$

As is readily apparent from equations (7) and (9), this price formula can be written as equation (8) if the effective rate of capital gains tax in equation (8) is defined in terms of the statutory rate, by

$$
t_{c}=t_{s}\left[\frac{r}{g}-1\right]\left[\frac{(1+r)^{i}-1}{(1+g)^{i}-1}-1\right]^{-1} .
$$

According to equation (11), given the relationship $r>g, t_{c}$ is at a maximum of $t_{\mathrm{c}}=t_{s}$ under annual trading $(i=1)$ and decreasing asymptotically to $t_{c}=0$ under indefinite deferral $(i=\infty)$. This formulation recognizes the effect of $g$ on $t_{c}$, unlike the traditional approach which describes $t_{c}$ as a discounted value of $t_{s}$, using $t_{c}=t_{s} /(1+r)^{i-1}$

\footnotetext{
${ }^{4}$ Note that equation (8) could be derived directly from equation (1) by substituting $g$ for $\left(P_{1}-P_{0}\right) / P_{0}$ and
} solving for $P_{0}$. The long method is used in analyzing below the effect of deferred trading. 
g., Bailey, 1969, Bierman and Hass, 1973, pp. 185-186, and King, 1977, pp. $-75)$.

The desired expression for the sheltered return earned by the fund is obtained by bstituting equation (8) for $P_{0}$ in equation (6), noting that $P_{1}=P_{0}(1+g)$,

$$
r_{s}=\frac{r-g\left(t_{d}-t_{c}\right)}{1-t_{d}}
$$

like $r_{s}$ in equation (4) obtained by the traditional approach, this rate depends on 2 rate of retention only to the extent that $b$ affects the stock's per-share growth e, $g$.

\section{Sheltered Personal Return}

The individual purchasing shares in a sheltered fund avoids payment of tax at the rsonal ordinary rate, $T_{d}$, on the initial contribution, but pays tax at the rate $T_{f}$ (at below the ordinary rate) at the time of distribution, plus a penalty excise tax at a ndard rate, $t_{x}$, on premature or late distributions. ${ }^{5}$ Consequently, the personal st-tax rate of return on an investment sheltered for $n$ years is given by

$$
\left(1+r_{p}\right)^{n}=\left(1+r_{s}\right)^{\prime \prime} \frac{\left(1-t_{x}\right)\left(1-T_{f}\right)}{1-T_{d}} .
$$

ith the use of a quotient, $q$, defined by $q=\left(1-t_{x}\right)\left(1-T_{f}\right) /\left(1-T_{d}\right)$, the personal e of return becomes

$$
r_{p}=\left(1+r_{s}\right) q^{1 / n}-1 \quad(q \geqq 1)
$$

tated as a function of the growth rate by substituting equation (12) for $1+r_{s}$,

$$
r_{p}=\left[1+\frac{r-g\left(t_{d}-t_{c}\right)}{1-t_{d}}\right] q^{1 / n-1 .}
$$

\section{Stock Growth and Personal Return}

Inspection of equations (15) and (11) indicates that $g$ affects $r_{p}$ both directly and lirectly, due to its effects on $t_{c}$ shown by equation (11). The total effect of $g$ on the isonal rate, $r_{p}$, is derived from an expanded version of equation (15) in which $t_{c}$ is slled out using equation (11),

$$
r_{p}=\left[1+g+\frac{r-g}{1-t_{d}}\left(1+t_{s} \frac{(1+g)^{i}-1}{(1+r)^{i}-(1+\mathrm{g})^{i}}\right)\right] q^{1 / n}-1 .
$$

There are differences between the various retirement plans regarding the tax treatment of mature distriions, the flexibility of reinstating an investment distributed prematurely, and the penalty on premature ate distributions. These differences affect the parameters $t_{x}$ and $T_{f}$. 
This expression is partially differentiated by $g$, using the simplified notations $R=$ $1+r, G=1+g, t=t_{d}$, and $\alpha t=t_{s}$ (assuming $0 \leq \alpha<1$ ),

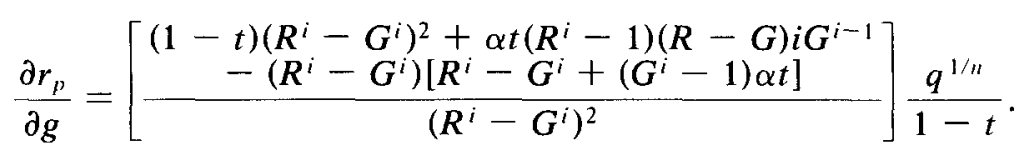

The sign of equation (17) depends on the sign of the numerator of the ratio enclosed in brackets, consisting of positive first and second terms and a negative third term. Determination of this sign is facilitated by substituting in the second term the positive $R^{i}-G^{i}$ for the smaller or equal $(R-G) i G^{i-1}$ and then dividing throughout by $\left(R^{i}-G^{i}\right)^{2}{ }^{6}$ The resulting expression is negative and greater than the above derivative,

$$
\frac{\partial r_{p}}{\partial g}<-\left[\frac{(1-\alpha) t}{1-t}\right] q^{1 / n}<0
$$

indicating an inverse relationship between $g$ and the personal rate, $r_{p}$, stated by equations (15) and (16), for any given $i(1 \leq i \leq \infty)$, subject to $0 \leq \alpha<1$. Since only the constant $q^{1 / n}$ is unique to the individual shareholder, the expression in brackets also indicates a negative relationship between $g$ and the fund's return $r_{s}$ stated by equations (6) and (12).

\section{Interpreting the Effect of Growth}

The demonstrated adverse effect of $g$ on $r_{s}$ and $r_{p}$, has important policy implications for optimal stock selection by the sheltered fund and fund selection by the individual seeking to maximize return. Other things being equal, a tax-sheltered fund should not invest in growth stocks because growth diminishes the return earned by the fund and its shareholders. Empirically, other things may not be equal; some growth stocks are likely to have risk-return characteristics making them an attractive addition to a diversified portfolio. The adverse effect of a stock's growth rate on its expected return is a factor that should be considered in building the portfolio of a tax-sheltered fund. In general, the optimal portfolio of such a fund would differ from that of unsheltered diversifiers. $^{\text {? }}$

Despite superficial similarity to the traditional approach, these conclusions flow

\footnotetext{
${ }^{\mathrm{h}}$ To prove that $R^{i}-G^{i} \geq(R-G) i G^{i-1}$ for admissible values of the parameters $R>G \geq 1$ and $i \geq 1$, define $M=R / G>1$, where the objective is to prove non-negativity of $f(M)=M^{i}-i M+i-1$. Partial differentiation by $M$ yields $\partial f(M) / \partial M=i M^{i-1}-i$, which can only be non-negative since a negative derivative would imply the impossible relationship $M^{i-1}<1$ subject to the constraints $M>1$ and $i \geq 1$. At the point $M=1 f(M)=0$, such that the demonstrated sign of $\partial f(M) / \partial M$ implies $f(M) \geq 0$ and, therefore. $R^{i}-G^{i} \geq(R-G) i G^{i-1}$. Q.E.D.

${ }^{7}$ Extending the post-tax CAPM constructed by Brennan (1970), Elton and Gruber (1978) develop a technique for portfolio optimization by an investor of any tax bracket that differs from that dominating the market equilibrium. The zero-bracket, tax-sheltered fund is a special case which can be treated by that technique, subject to the limiting assumptions inherent to the CAPM.
} 


\section{IRA and Keogh Should Avoid Growth Stocks}

from different quantitative results and are based on different reasoning. Under the traditional approach, the inverse effect of retention on return in equation (5) follows immediately from the claim that retention decreases the tax burden in equation (1). Under the present analysis, the inverse effect in equation (18) holds despite the price formulation of equation (8), showing that retention and growth increase that burden. The explanation for this apparent conflict between equations (8) and (18) requires a closer look at the interaction between growth and taxes in a tax-sheltered environment.

According to equations (6), (12), and (15), the rate of return earned by the fund can be partitioned into a dividend yield and a capital gain,

$$
r_{s}=\frac{D}{P_{0}}+\frac{P_{1}-P_{0}}{P_{0}}=\frac{r-g\left(1-t_{c}\right)}{1-t_{d}}+g .
$$

The first component showing the dividend yield is traced to equation (8). It is the difference between the post-tax return earned by taxpaying shareholders, $r$, and the growth rate trimmed by the capital gains tax. Since the fund is sheltered from the dividend tax, the dividend yield is "grossed up" by the factor $1-t_{t l}$. The second component is the tax-sheltered rate of capital gain. These effects are confirmed by comparing the sheltered return and the unsheltered return derived from equation (8) in the same form,

$$
r=\frac{D\left(1-t_{d}\right)}{P_{0}}+\frac{\left(P_{1}-P_{0}\right)\left(1-t_{c}\right)}{P_{0}}=\left[r-g\left(1-t_{c}\right)\right]+g\left(1-t_{c}\right) .
$$

This comparison reveals that in both cases growth has conflicting effects on return. The effects of $g$ on the unsheltered return exactly offset each other, while those on the sheltered return do not. The net effect of growth on the sheltered return is clear from equations (12) and (15), where $r_{s}$ is stated as

$$
r_{s}=\frac{r-g\left(t_{d}-t_{c}\right)}{1-t_{d}}
$$

Given $t_{d}>t_{c}$, for any holding period $i$ the presence of $g>0$ causes $r_{s}<r /\left(1-t_{d}\right)$, namely a net decrease in return compared to its rate under $g=0$, where $r_{s}=$ $r /\left(1-t_{d}\right)$.

Equations (12) and (15) in conjunction with equation (11) further reveal that the adverse effect of growth on return is partially decreasing in $t_{s}$ and increasing in $t_{d}$ and $i$. Given the ratio between the two statutory tax rates, $\alpha=t_{s} / t_{d}$, it can be demonstrated using equation (17) that this effect is also increasing in the marginal tax bracket, $t=t_{d}$.

\section{IIlustration}

The adverse effect of $g$ on $r_{s}$ is illustrated in Figure I, drawn on the basis of equations (11) and (12) subject to the following parameters. The holding period $i=1$ is 


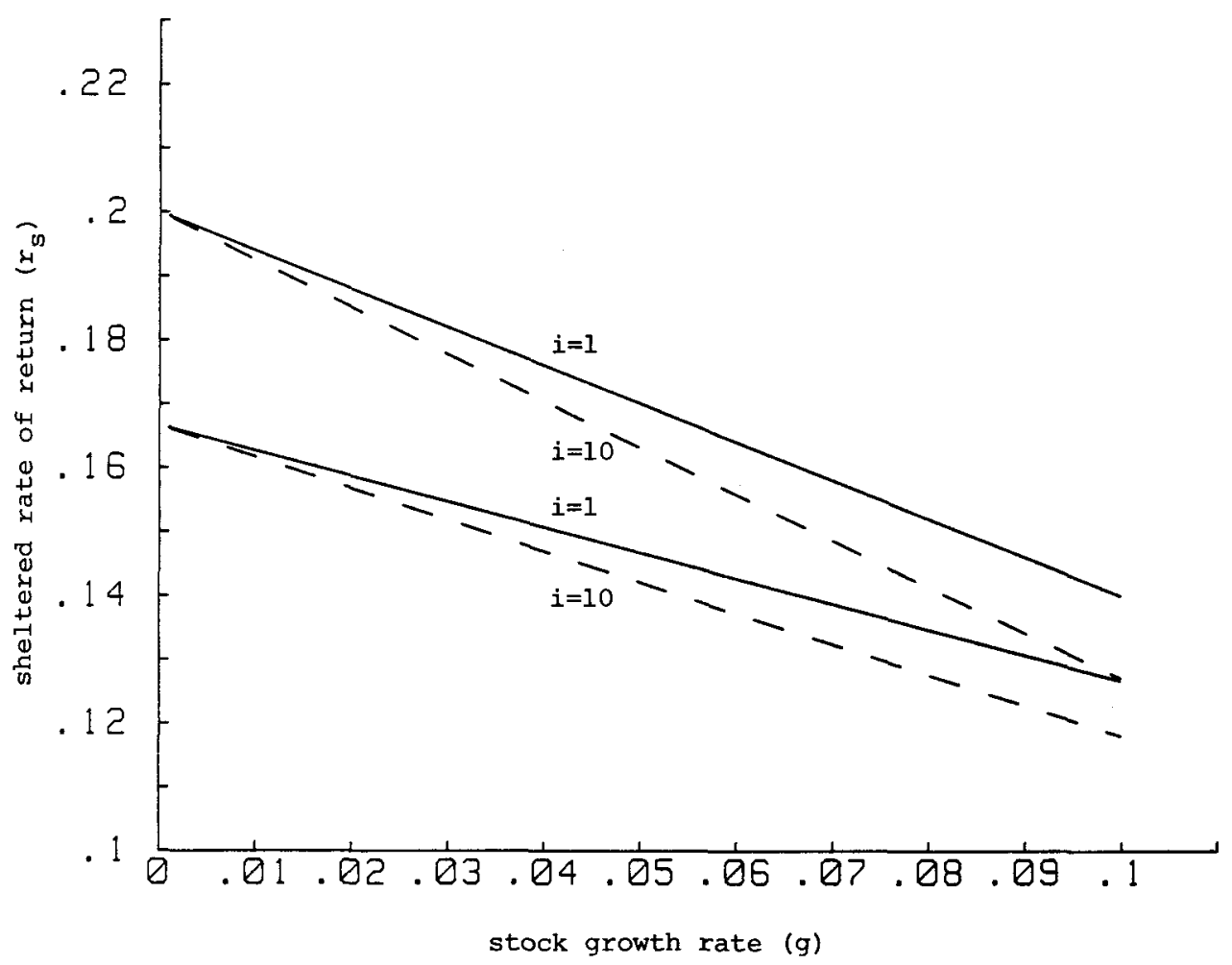

Figure I. The Adverse Effect of Growth on Sheltered Return.

used in the pair of solid lines, and $i=10$ in the pair of broken lines. In each pair, the tax rates $t_{d}=.5$ and $t_{s}=.2$ are used in the top line, and $t_{d}=.4$ and $t_{s}=.16$ in the bottom line. The growth rate ranges between $g=0$ and $g=.1$, while the discount rate is fixed at $r=.1$.

Figure I reveals that the effect of $g$ on $r_{s}$ is substantial and close to linear even if the dominant holding period is as high as $i=10$. Given $t_{d}=.5, t_{s}=.2$, and $i=1$, the maximum increase in $g$ from $g=0$ to $g=.1$ causes a decrease in $r_{s}$ from .2 to .14 . A smaller increase in $g$ would cause a proportionately smaller decrease in $r_{s}$.

This effect is strengthened under the longer holding period $i=10$. The same maximum increase in $g$ causes a greater decrease in $r_{s}$ from .2 to below .13. These effects only slightly diminish under the lower tax rates $t_{d}=.4$ and $t_{s}=.16$.

\section{Retirement Funds as a Temporary Tax Shelter}

Temporary investment in tax-sheltered funds is superior to unsheltered investment if the advantage derived from the higher return exceeds the tax penalty on early withdrawal. An investor seeking a temporary tax shelter over $n$ years must determine the minimum period $n *$ making such an investment profitable. This time period is unique to the individual and can easily be calculated from equation (15) if the penalty and 
other personal tax rates determining $q$ are themselves independent of the investment period up to the critical $n^{*}$.

To derive $n^{*}, r_{p}$ stated by equation (14) is set equal to $r$ and solved for $n=n^{*}$,

$$
n^{*}=\frac{\ln (q)}{\ln (1+r)-\ln \left(1+r_{s}\right)} \quad\left(n^{*}>0 ; r_{s}>r ; q<1\right)
$$

where the denominator and admissible values of the numerator are negative, such that $n^{*}>0$. Based on $q=\left(1-t_{x}\right)\left(1-T_{j}\right) /\left(1-T_{d}\right)$ and the constraint $q<1$ implied by $n^{*}>0, n^{*}$ is partially increasing in the standard penalty rate, $t_{x}$, and the personal tax rate avoided on initial investment, $T_{d}$. Predictably, $n *$ is also decreasing in the rate of return earned by the sheltered fund, $r_{s}$, and increasing in the unsheltered opportunity rate of return, $r$.

\section{IIlustration}

The factors determining $n^{*}$ are illustrated in Figure II, drawn on the basis of equations (13) and (19). Each of the three curves shows the effect of a change in the positive difference $\ln \left(1+r_{s}\right)-\ln (1+r)$ on $n^{*}$, holding $q$ constant at the reasonable values

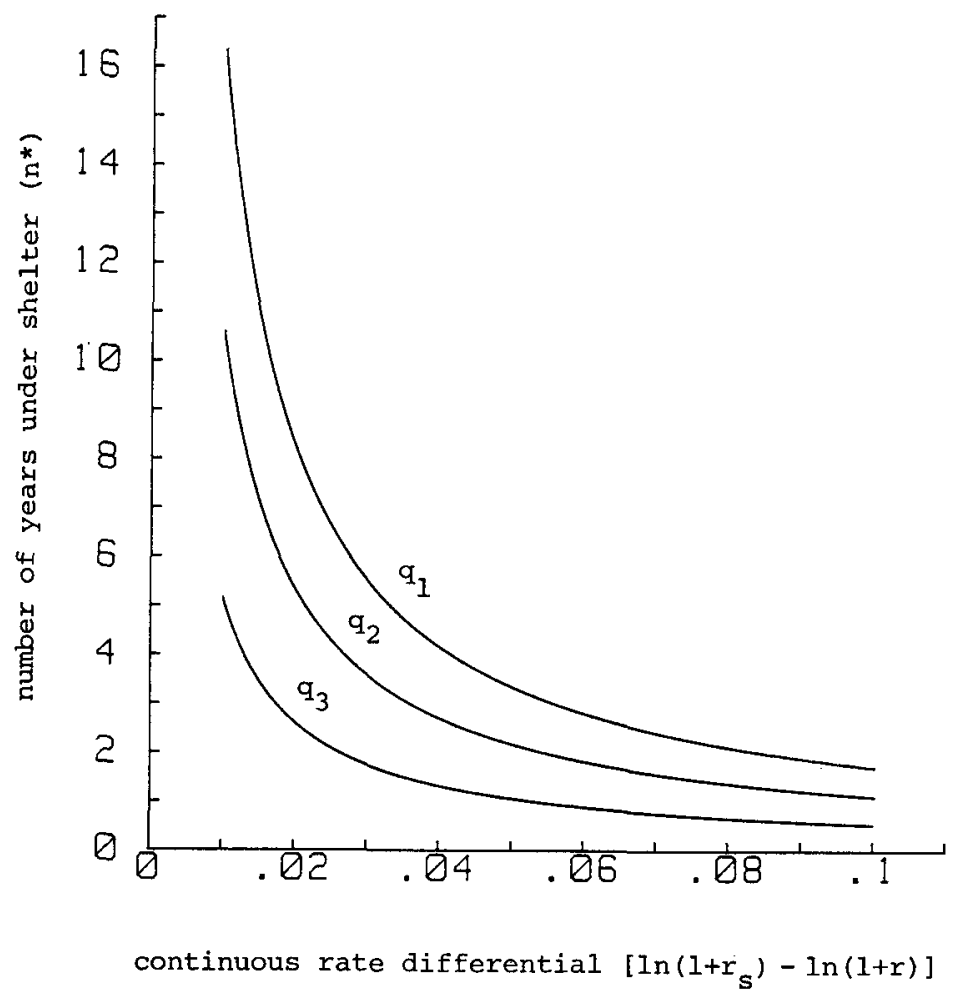

Figure II. The Minimum Period for Profitable Sheltering of Investment. 
(starting from the top) $q_{1}=.85, q_{2}=.90$, and $q_{3}=.95$. The difference $\ln \left(1+r_{s}\right)-$ $\ln (1+r)$, which can be interpreted as the difference between the continuous equivalents of the discrete rates $r_{s}$ and $r$, has realistic values between 0 and .15 .

Figure II indicates that the critical investment period may be very low. For example, the parameter $t_{x}=.1$ in combination with the assumption of $T_{f}=T_{d}$ implies $q=$ $q_{2}=.90$. The additional parameters $r=.10$ and $r_{s}=.13$ imply $n *=3.92$, namely a premature withdrawal after four years would allow the investor to pay the 10 -percent tax penalty and still break even.

\section{Summary}

This paper explores the effect of personal taxation of income from common stocks on the return of equity portfolios held by mutual funds under IRA or Keogh plans. The expected rate of return earned by a tax-sheltered fund on any given stock is inversely related to the stock's per-share growth rate. The explanation provided for this effect does not rely on the usual assumption that growth stocks are subject to a lesser tax burden. Rather, this effect is shown to hold despite heavier taxation of growth stocks because of the incomplete manner in which the return is sheltered. Numerical examples indicate that the adverse effect of growth on tax-sheltered return is substantial and should not be ignored in selecting stocks for a sheltered portfolio. This finding is difficult to reconcile with evidence showing that equity funds under IRA and Keogh plans tend to be concentrated in growth stocks.

A second issue examined in this paper is the use of IRA and Keogh plans as a temporary tax shelter. Under the present 10 -percent penalty on premature distribution, the critical investment period may be as short as two or three years. This finding indicates the usefulness of these plans as a general investment tool.

\section{References}

Arditti, F. D., Levy, H., and Sarnat, M. (1976) "Taxes, Uncertainty, and Optimal Dividend Policy." Financial Management, (Spring), pp. 46-52.

Bailey, M. J. (1969) "Capital Gains and Income Taxation." In A. C. Harberger and M. J. Bailey (eds.) Taxution of Income from Capital, Washington, D.C.: The Brookings Institution.

Bierman, H. and Hass, J. E. (1973) An Introduction to Managerial Finance, New York: Norton and Co.

Black, F. and Scholes, M. (1974) "The Effects of Dividend Yield and Dividend Policy on Common Stock Prices and Returns." Journal of Financial Economics, (May), pp. 1-22.

Brennan, M. J. (1970) "Taxes, Market Valuation and Corporate Financial Policy." National Tax Journal, (December), pp. 417-427.

Donoghue, W. E. (with Tilling, T.) (1983) No Load Mutual Fund Guide, New York: Harper and Row.

Elton, E. J. and Gruber, M. J. (1978) "Taxes and the Portfolio Composition." Journal of Financial Economics, (December), pp. 399-410.

Feldstein, M. S. and Green, J. (1983) "Why Do Companies Pay Dividends?" American Economic Review, (March), pp. 17-30.

Feldstein, M. S., Green, J., and Sheshinski, E. (1979) "Corporate Financial Policy and Taxation in a Growing Economy." Quarterly Journal of Economics, (August), pp. 411-432.

King, M. A. (1977) Public Policy and the Corporation, London: Chapman and Hall. 


\section{IRA and Keogh Should Avoid Growth Stocks}

Litzenberger, R. and Ramaswamy, K. (1979) “The Effect of Personal Taxes and Dividends on Capital Asset Prices: Theory and Empirical Evidence." Journal of Financial Economics, (June), pp. 163-195.

Long, J., Jr. (1978) "The Market Valuation of Cash Dividends: A Case to Consider." Journal of Financial Economics, (December), pp. 235-264.

Miller, M. H. (1977) "Debt and Taxes." Journal of Finance, (May), pp. 261-275.

Miller, M. H. and Scholes, M. (1978) "Dividends and Taxes." Journal of Financial Economics, (December), pp. 333-364.

Miller, M. H. and Scholes, M. (1982) "Dividends and Taxes: Some Empirical Evidence." Journal of Political Economy, (December), pp. 1118-1141.

Mutual Fund Fact Book. (1982-1985) Washington, D.C.: Investment Company Institute.

Palmon, D. and Yaari, U. (1981) "Retention and Tax Avoidance: A Clarification." Financial Management, (Spring), pp. 29-35.

Palmon, D. and Yaari, U. (1983a) "Taxation of Capital Gains and the Behavior of Stock Prices over the Dividend Cycle." American Economist, (Spring), pp. 13-22.

Palmon, D. and Yaari, U. (1983b) "Personal Taxes and the Fair Rate of Return Doctrine." Financial Review, (May), pp. 167-174.

Yaari, U., Palmon, D., and Marcus, M. (1980) "Stock Prices under Inflation with Taxation of Noninal Gains." Financial Review, (Winter), pp. 38-54. 